\title{
A benzedura nos territórios da Estratégia Saúde da Família: percepções de trabalhadores, usuários e benzedores
}

\author{
Healing blessing in territories of the Family Health Strategy: \\ perceptions of workers, users and healers
}

Luiza Maria de Assunção', Rosimár Alves Querino², Leiner Resende Rodrigues²

DOI: $10.1590 / 0103-1104202012613$

\begin{abstract}
RESUMO Vinculada à cultura brasileira, a benzedura é uma linguagem simbólica relevante e diferencial no papel de escuta e cuidado. O estudo teve por objetivo capturar os impactos da benzedura nos territórios da Estratégia Saúde da Família em município mineiro e analisar a relação entre os componentes do campo religioso e do campo médico-científico. Trata-se de estudo descritivo e exploratório, de natureza qualitativa, aprovado por comitê de ética. Realizaram-se 35 entrevistas semiestruturadas e empregou-se a análise temática para sua interpretação. Como aporte teórico, tomou-se o pensamento de Pierre Bourdieu sobre a disputa entre os campos de saber. Emergiram três categorias: Representações sobre a prática; Saúde e religiosidade/espiritualidade; Relações com a benzedura. A prática da benzedura é enxergada como parte da cultura. Destacou-se o seu impacto no resgate da dimensão subjetiva do cuidado, atuando na escuta, apoio, conforto, fortalecimento e desmedicalização. Consorciada à medicina, é ajuda adicional que enseja trabalhar a totalidade. A relação entre campo religioso e campo médico-científico por meio da benzedura propicia a diluição do conflito. Esta pesquisa propulsionará outros estudos na temática de terapias populares e produção de saúde e cuidado, bem como sobre a relação entre saúde e Religiosidade/ Espiritualidade.
\end{abstract}

PALAVRAS-CHAVE Atenção Primária à Saúde. Estratégia Saúde da Família. Medicina tradicional.

\begin{abstract}
The traditional practice of healing blessing (benzedura) existing within the Brazilian culture is a relevant symbolic expression and a differential in the role oflistening and caring. This study aimed to capture the impacts of this practice in territories attended by the Family Health Strategy in the state of Minas Gerais, Brazil, analyzing the relationship between the components of religious and medical-scientific fields. This is a descriptive exploratory study involving a qualitative approach, approved by an Ethics Committee. Data were collected through 35 semi-structured interviews, using the thematic analysis for interpretation. The theoretical framework draws on the thought of Pierre Bourdieu on the dispute between fields of knowledge. Three categories emerged: Representations of the practice; Health and Religiosity/Spirituality; Relationship with healing blessing. The study highlighted the impact of blessing in the rescue of the subjective dimension of care, working on listening, support, comfort, strengthening and demedicalization. Associated to medicine, blessing means additional help that entails working the human being in his/her totality. The relationship between religious and medical-scientific fields mediated by blessing points to a dilution of the conflict. This research will propel other studies on popular therapies and health and care production, as well as on the relationship between health and Religiosity/Spirituality.
\end{abstract}

1Universidade do Estado
de Minas Gerais (Uemg) Ituiutaba (MG), Brasil.

luassunc@gmail.com

2 Universidade Federal do Triângulo Mineiro (UFTM)

- Uberaba (MG), Brasil.
KEYWORDS Primary Health Care. Family Health Strategy. Medicine, traditional. 


\section{Introdução}

Nos últimos tempos, as benzedeiras têm conseguido espaço no sentido da regulamentação da sua prática. No município de Rebouças (PR), foi oficializada a atuação de benzedeiras, consideradas subsídio à saúde pública $\mathbf{1}$. Em Sobral (CE), de modo similar, benzedeiras foram incorporadas ao sistema de saúde, desempenhando papel de Agentes Não Formais de Cura (ANFC) e reconhecidos como parte da cultura local2 .

Religiosidade/Espiritualidade (R/E) têm o poder de dar significados às demandas dos sujeitos. A eficácia simbólica por trás das diferentes crenças está relacionada à compreensão do evento que acomete o sujeito, e tal compreensão se dá de modo metafórico e não racional ${ }^{3}$. Por sua vez, o saber biomédico, mediante prática homogeneizadora e perspectiva hospitalocêntrica, costuma ignorar "as complexas problemáticas da contemporaneidade"4(178), enfraquecendo o potencial cultural e simbólico dos sujeitos e destituindo-os de autonomia para enfrentar situações que envolvam sofrimento, doenças e morte.

O norte teórico-metodológico deste estudo fundamenta-se na teoria da prática de Pierre Bourdieu 5 , que adota como um dos motes de reflexão a autonomia dos diferentes campos que compõem o mundo social, que possuem funcionamento interno próprio e disputam em torno da legitimidade em dizer a verdade ${ }^{5}$. Neste caso, a intenção é refletir sobre a relação entre o campo da saúde, representado pelos trabalhadores da Estratégia Saúde da Família (ESF), e o campo religioso, representado por benzedeiras e benzedores, de modo a apresentar o tipo de interlocução efetuada entre o saber biomédico e o saber religioso.

Atento à realidade de possíveis influências da R/E na saúde, este estudo objetivou capturar os impactos da benzedura nos territórios da ESF em município mineiro e analisar a relação entre os componentes do campo religioso e do campo médico-científico.

\section{Material e métodos}

Trata-se de estudo descritivo e exploratório, de natureza qualitativa, que traz a interface entre as ciências sociais e a saúde coletiva, realizado com Equipes Saúde da Família (EqSF) de município do Triângulo Mineiro, Minas Gerais.

A população foi composta por Agentes Comunitários de Saúde (ACS), médicos, dentistas, enfermeiros, técnicos de enfermagem, usuários e benzedeiras e benzedores pertencentes às 51 EqSF de três distritos sanitários de município mineiro. Incluíram-se trabalhadores que atuavam na instituição de saúde há, pelo menos, um ano; usuários que utilizavam o serviço há, pelo menos, um ano e residiam no município; benzedeiras e benzedores que atuavam em área coberta pela ESF, exerciam o ofício há, pelo menos, um ano e residiam no município. Foram excluídos informantes menores de 18 anos de idade e trabalhadores em licença de saúde. As 51 equipes foram percorridas e delas sortearam-se, para entrevistas áudio gravadas, duas equipes de cada distrito sanitário e uma da zona rural.

A amostra foi constituída por 35 sujeitos sorteados de $51 \mathrm{EqSF}$ que atenderam aos critérios de inclusão. Foram entrevistados: seis médicos e um dentista; seis enfermeiros e um técnico de enfermagem; sete ACS; sete benzedeiras e benzedores e sete usuários. Para as entrevistas gravadas em áudio, utilizou-se um roteiro semiestruturado de questões.

A coleta de dados ocorreu no período de outubro de 2016 a janeiro de 2017, nas Unidades Básicas de Saúde (UBS) e nas residências de usuários e de benzedeiras e benzedores.

O processo de coleta de dados foi encerrado a partir do nível de saturação teórica ${ }^{6}$. A apreciação do material coletado aconteceu por meio de análise temática ${ }^{7}$.

Os sujeitos foram convidados a participar da pesquisa, sendo informados quanto aos objetivos e procedimentos. Para resguardar sua identidade, foram identificados por letras, seguidas da ordem na qual foram realizadas as entrevistas: ACS (A1, A2...); Benzedeiras e 
Benzedores (B1, B2...); Enfermeiros (E1, E2...); Médicos (M1, M2...); Usuários (U1, U2...).

A pesquisa foi aprovada por Comitê de Ética em Pesquisa sob o protocolo $\mathrm{n}^{\mathrm{o}}$ 1.774.886. O termo de consentimento Livre e Esclarecido (TCLE) foi assinado por todos os participantes da pesquisa, seguindo-se os preceitos estabelecidos pela Resolução $n^{\circ} 466 / 128$.
Da análise temática, emergiram três categorias: (1) Representações sobre a prática; (2) Saúde e R/E; (3) Relações com a benzedura. Procedeu-se à separação dessas categorias em dois temas: a benzedura no campo religioso (Tema I); e campo científico e campo religioso (Tema II). Todas as informações da pesquisa de campo estão tabuladas no quadro 1 .

Quadro 1. Categorias temáticas obtidas a partir das entrevistas com trabalhadores da ESF, benzedeiras/benzedores e usuários

\begin{tabular}{|c|c|c|c|c|}
\hline Tema & Categorias & Subcategorias & Conceito norteador & Depoentes \\
\hline \multirow[t]{4}{*}{$\begin{array}{l}\text { A benzedura no } \\
\text { campo religioso }\end{array}$} & $\begin{array}{l}\text { (1) } \\
\text { Representações } \\
\text { sobre a prática }\end{array}$ & $\begin{array}{l}\text { Tradição familiar e } \\
\text { oral }\end{array}$ & $\begin{array}{l}\text { Apresenta a característica não letrada da ben- } \\
\text { zedura, transmitida oralmente de geração a } \\
\text { geração. }\end{array}$ & $\mathrm{B} 1 ; \mathrm{B} 2 ; \mathrm{B} 3 ; \mathrm{B} 5 ; \mathrm{B} 6 ; \mathrm{B} 7$ \\
\hline & & Dom & $\begin{array}{l}\text { Denota o caráter particular daquele que exerce } \\
\text { a benzedura, que deve possuir a aptidão para } \\
\text { o ofício. }\end{array}$ & $\mathrm{B} 1 ; \mathrm{B} 2 ; \mathrm{B} 3 ; \mathrm{B} 4 ; \mathrm{B} 5 ; \mathrm{B} 6 ; \mathrm{B} 7$ \\
\hline & & Herança cultural & $\begin{array}{l}\text { Salienta a benzedura como parte da cultura } \\
\text { religiosa brasileira, algo entranhado na mentali- } \\
\text { dade da população. }\end{array}$ & 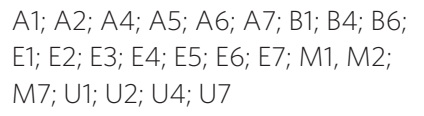 \\
\hline & & Papel desempenhado & $\begin{array}{l}\text { Apresenta as direções em que a benzedura } \\
\text { atua na vida dos sujeitos e quais os benefícios } \\
\text { proporcionados. }\end{array}$ & 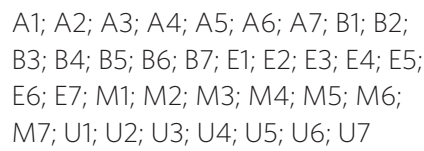 \\
\hline \multirow[t]{4}{*}{$\begin{array}{l}\text { Campo científico } \\
\text { e campo religioso }\end{array}$} & $\begin{array}{l}\text { (2) } \\
\text { Saúde e R/E }\end{array}$ & $\begin{array}{l}\text { Deficits e desafios do } \\
\text { trabalho em saúde } \\
\text { e R/E }\end{array}$ & $\begin{array}{l}\text { Denota as dificuldades e obstáculos que sur- } \\
\text { gem na tentativa de estabelecer um trabalho } \\
\text { focado na interface saúde e R/E. }\end{array}$ & $\begin{array}{l}\text { A2; } A 3 ; A 4 ; A 6 ; A 7 ; E 1 ; E 2 ; E 3 ; E 4 ; \\
E 5 ; E 6 ; E 7 ; M 1 ; M 2 ; M 3 ; M 4 ; M 6 ; \\
M 7 ; \cup 7 .\end{array}$ \\
\hline & & $\begin{array}{l}\text { Ganhos e potenciali- } \\
\text { dades do trabalho em } \\
\text { saúde e R/E }\end{array}$ & $\begin{array}{l}\text { Indica as conquistas advindas de um trabalho } \\
\text { focado na interface saúde e R/E. }\end{array}$ & $\begin{array}{l}\text { A1; } A 2 ; A 4 ; A 5 ; A 7 ; E 1 ; E 2 ; E 3 ; E 4 ; \\
E 5 ; E 6 ; E 7 ; M 1 ; M 2 ; M 3 ; M 4 ; M 5 ; \\
M 6 ; M 7 ; \cup 1 ; \cup 4 ; U 5 ; \cup 7\end{array}$ \\
\hline & $\begin{array}{l}\text { (3) } \\
\text { Relações com a } \\
\text { benzedura }\end{array}$ & Conflito & $\begin{array}{l}\text { Salienta a existência de conflitos inevitáveis } \\
\text { quando se colocam as práticas médicas e a } \\
\text { benzedura lado a lado. }\end{array}$ & $\begin{array}{l}\text { B2; B7; E1; E2; E3; E4; E5; E7; M2; } \\
\text { M3; M4; M5; M6; M7 }\end{array}$ \\
\hline & & Diálogo & $\begin{array}{l}\text { Salienta o diálogo possível entre as práticas } \\
\text { médicas e a benzedura, a despeito das suas } \\
\text { particularidades. }\end{array}$ & 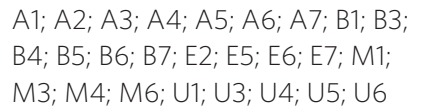 \\
\hline
\end{tabular}

Fonte: Elaboração própria. 


\section{Resultado e discussão}

\section{A benzedura no campo religioso}

\section{REPRESENTAC̣̃̃ES SOBRE A PRÁTICA}

A benzedura é referida como uma 'tradição familiar e oral', repassada no interior do círculo familiar ou por pessoas próximas por meio da oralidade. A benzedura é uma prática que se compôs ao longo dos séculos, tornando-se parte da cultura popular e religiosa do Brasil ${ }^{9}$. Esse ofício, constituído por rezas e saberes de cura, é ensinado por uma pessoa mais velha, geralmente da família, que se esforça para manter vivo esse saber nas futuras gerações ${ }^{9-13}$. Os gestos ritualísticos, as rezas recitadas, acontecem mediante a oralidade $\mathrm{9}^{\mathbf{9} 10,14}$, sendo característica das benzedeiras não saber justificar as suas práticas, alegando que foi assim que aprenderam ${ }^{\mathbf{1 4}}$.

Essa prática é percebida como um 'dom', remetendo ao caráter singular daquele que a exerce, que deve possuir aptidão para o ofício. Estudo confirma se tratar de um saber relacionado ao dom 9-13, caracterizado como uma "arte de curar"12(114), onde seus representantes agem como protagonistas da história da medicina e são mais antigos do que os próprios médicos científicos ${ }^{15}$.

Relacionada ao dom, outra característica da prática da benzedura é a sua gratuidade. Para se iniciar nesse ofício, é condição sine qua non que o benzimento seja realizado gratuitamente, visto que o oficiante recebe de Deus esse dom, não podendo cobrar qualquer valor ${ }^{2,9}$. Ou seja, impera nessa prática um caráter altruísta9,12, desprovido de remuneração 9 . Acreditase, nessa direção, que a benzedura varia entre um dom e um ofício, onde a benzedeira passa a encarar o dom como um dever de ajudar outras pessoas num ato de generosidade, sem cobrança de qualquer valor ${ }^{9,11}$.

A busca pela benzedura é uma 'herança cultural'. De acordo com os informantes, a tradição e a eficácia relacionadas à benzedura estimulam a levar as crianças para se benzer de cobreiro, dor de barriga, mal olhado, mal de simioto, espinhela caída, quebranto, mal olhado, vento virado.

Esse ofício possui mais efeito em certas situações e enfermidades e está relacionado a questões culturais que envolvem crença e fé transmitida pelos antepassados. A benzedura, existe desde o Brasil colônia ${ }^{12}$, despontando como uma prática ritual constitutiva da nossa cultura e como uma forma de cuidado ${ }^{\mathbf{1 0} 12}$. Reconhecida como prática tradicional escolhida para superar enfermidades que acometem especialmente às crianças ${ }^{\mathbf{1 3}}$, a benzedura também está relacionada a outras doenças, como cobreiro, mal olhado, espinhela caída, machucadura, rendidura, todas denominadas 'doenças de benzedeiras'16. De acordo com Santos9, as enfermidades tratadas pelas benzedeiras não fazem parte do conjunto de doenças que compõem o campo da medicina; ao contrário constituem o rol dos males que integram o universo cultural da população?.

A despeito das demandas a ela relacionadas, a prática da benzedura escasseou, num movimento de extinção que se perpetua gradativamente: "As coisas vão acabando sem a pessoa perceber. No meu caso, se eu não passar para ninguém, eu vou enterrar comigo" (B6). Já é um consenso entre as próprias benzedeiras de que seu ofício está desaparecendo". Acredita-se que isso ocorra devido à não transmissão desse saber no interior da família, em função de desinteresse dos descendentes, como acontecia antigamente $\mathrm{e}^{\mathbf{1 0} 13}$. Ainda assim, tem havido esforços para resgatar esse ofício, tido como cultura imaterial, e levar a cabo a sua valorização como saber popular ${ }^{\mathbf{1 2}}$.

Com relação ao 'papel desempenhado pelo ofício da benzedura', esta atua em questões diversificadas: conflitos familiares e problemas pessoais; ineficácia médica e dos medicamentos; procura por emprego, saúde e sucesso na escola; para tratar os filhos e netos; para tratar algum motivo de enfermidade; por necessidade de escuta, apoio e acolhimento. A procura por 
esse ofício está direcionada a aplacar anseios e à resolução instantânea de problemas os mais diversos ${ }^{9}$. Os sujeitos demandam por tecnologias leves voltadas para relações, produção de vínculo e acolhimento ${ }^{\mathbf{1 7}}$, exatamente como efetuado pela benzedura, que alcança as dimensões objetiva e subjetiva no contexto 'do cuidado vivo em ato para afirmação da vida'18.

Percebida como um recurso preventivo para não ser necessário ir ao médico, a benzedura exerce interferência positiva na saúde, fortalecendo, ajudando e orientando em todos os sentidos. Ela proporciona alívio, bem-estar, paz, tranquilidade, calma, refúgio e exerce papel importante na parte física, psicológica e espiritual. O apoio psicológico se destaca, indicando a sua atuação no amparo emocional global, na catarse ou descarrego, na melhora do estado de ânimo e da autoestima. Na condição de suporte e amparo, a benzedura promove força, escuta, acolhimento, orientação, assim como bem-estar e alívio relacionados ao conforto emocional, resultando na melhora dos sintomas ${ }^{10}$. Em última instância, dispensa solução aos problemas do corpo e da alma ${ }^{9,12,16}$.

Acredita-se que a benzedura por meio do uso de ervas e chás medicinais, devido à simplicidade associada ao tipo de tratamento não convencional que ela confere, auxilia em direção à desmedicalização e à fuga da cultura do medicamento. Indicadas como coadjuvantes do processo de desmedicalização ${ }^{19}$, benzedeiras têm o hábito de receitar chás ${ }^{19}$; recursos de natureza terapêutica e comuns nas áreas da atenção básica, onde são entendidos como atitude de autocuidado que propicia autonomia aos sujeitos ${ }^{\mathbf{2 0}}$. Além disso, o uso de chás e plantas apresenta um significado antropológico, na medida em que proporciona o resgate e a validação dos saberes populares, fato que promove a autoestima na população marginalizada no seu saber específico ${ }^{20}$.

A procura pela benzedura ocorre também em substituição ao atendimento público de saúde, devido à decepção e frustração com a prática médica convencional, ao tempo de espera, ao difícil acesso aos serviços de saúde e à sua defasagem. No que diz respeito à resolutividade, a benzedura foi durante longa data a única possibilidade para pessoas desprovidas de cuidado por questões geográfica ou social, sendo o único recurso disponível para a proteção e o fortalecimento ${ }^{\mathbf{1 2}}$.

Ao funcionar como um recurso proporcionado pela própria comunidade, com dispositivos como escuta e acolhimento, benzedeiras e benzedores podem cumprir papel na orientação e encaminhamento dos usuários para as UBS, desempenhando o papel de 'um olhar' sobre a comunidade (M2) e auxiliando no acesso ao paciente. Nesse sentido, a fala de M2 revela o necessário acolhimento da crença para trazer os usuários para junto dos trabalhadores:

Toda benzedeira tem essa coisa de falar: 'Agora é só a parte divina, de Deus e tudo, eu ajudo. Eagora é a sabedoria dos homens'. Então, a benzedeira não vai tratar alguém que está super mal. Ela sempre orienta. Ela é essa que encaminha para gente. Então eu acho que ela é um olhar que a gente tem ali na comunidade. (M2).

Eu não questiono se ela está bebendo a água com quiabo dela, deixa beber. Se ela acredita, ela tem fé, se ela faz a benzeção, eu não questiono isso. $E$ melhor eu tentar tê-los mais perto com a crença deles e tudo e para manter também o acompanhamento que a gente faz. (E4).

Além de possuírem intimidade com a esfera curativa e de cuidado, benzedeiras são reconhecidas e respeitadas na comunidade, encarregando-se gratuitamente da saúde da população ${ }^{18}$. De certa forma, elas abraçam o papel de agentes públicos de saúde sem, no entanto, possuírem oficialmente essa insígnia, penetrando no cotidiano dos sujeitos ${ }^{11}$. São reconhecidas por sua habilidade para decifrar doenças e informar à população e aos agentes de saúde ${ }^{2}$, dando significado às situações do cotidiano, promovendo esperança, conferindo direcionamento e orientação aos sujeitos ${ }^{11}$. 


\section{Campo científico e campo religioso}

\section{SAÚDE ER/E}

Relativamente aos 'Deficits e desafios do trabalho em saúde e R/E', considera-se que haja carência de treinamento e capacitação no trato da temática R/E, o que resulta em não acolhimento das necessidades religiosas ou espirituais dos usuários. Não é ofertada formação sobre aspectos religiosos nos cursos de graduação, pois as intervenções dos trabalhadores junto aos usuários ocorrem em função apenas da ética pessoal e do bom senso, dependendo de seus valores subjetivos e de sua vivência ou experiência própria, de conhecimento vindo dos antepassados. Assim, corre-se o risco de impor tratamentos desconsiderando os valores dos usuários. Tem havido projetos e propostas incipientes relacionados à humanização e à espiritualidade, embora note-se a necessidade de haver formação para que os trabalhadores aprendam a respeitar os diferentes credos e a trabalhar holisticamente as demandas:

A gente ainda forma o profissional para medicar/ internar/segmentar um indivíduo em partes, para cada um ver o seu lado/campo. As práticas holísticas ainda não são um objeto de formação na universidade. (M4).

A desconsideração da R/E ocorre não necessariamente por displicência, mas porque os trabalhadores não sabem como introduzir tal assunto e pelo receio da consequência dessa inclusão ${ }^{21}$. A importância da dimensão espiritual tem feito com que estudiosos proponham a implantação da disciplina 'Espiritualidade e saúde' junto aos cursos de saúde. Acredita-se que possa estar havendo elevada demanda em relação ao trabalho com $\mathrm{R} / \mathrm{E}$ na atenção à saúde e que, entretanto, não existam tantos trabalhadores preparados para absorver tamanha demanda ${ }^{22}$.

Alguns trabalhadores afirmam não ser colocado em prática o acolhimento em relação às questões religiosas ou espirituais, restringindo-se apenas à medicalização, num processo que se resume "à receita e tchau" (A6). Ainda que se tenha constatado, mediante os censos, o aumento do número de pessoas que se autodenominam sem religião, o Brasil permanece aflorado de religiosidade, a qual transpassa a cultura e integra o dia a dia dos sujeitos ${ }^{22}$. Ter entendimento e abertura para questões relacionadas à $\mathrm{R} / \mathrm{E}$ dá possibilidade aos trabalhadores da saúde de ofertarem uma terapêutica, valorizando a crença do usuário, sem, no entanto, desvalorizar o saber médico ${ }^{22}$.

A R/E é vista como prejudicial quando há excessos. Se houver obsessão pela prática religiosa, pode ocorrer interferência negativa no sentido da suspensão da medicação ou do adoecimento e sofrimento em razão da religião. A R/E pode ser prejudicial a partir do momento em que os sujeitos assumem um posicionamento passivo em relação ao tratamento, transferindo a responsabilidade pela sua cura a um ser transcendente, denominado coping-religioso negativo ${ }^{23}$. Nesse sentido, é importante que os trabalhadores da saúde tenham conhecimento sobre aspectos relacionados à R/E, pois assim eles terão condições de intervir em situações em que a religiosidade esteja sendo prejudicial22.

Relativamente aos 'Ganhos e potencialidades do trabalho em saúde e R/E', afirma-se que a fé, de modo geral, tem impacto positivo na vida das pessoas. A R/E, desde que não haja exageros, pode ser positiva e, assim como a medicina, proporcionar terapêutica: "Quando a gente pega um paciente com uma doença crônica, aquele que tem fé interpreta de uma forma diferente. Não sei se ele aceita/ suporta" (M2). Esse impacto positivo da R/E ocorreria de diversas formas: na melhoria de um quadro de enfermidade; no recuo de doenças e mal-estares; na parte psicológica do como desabafar as suas dores; na abordagem integral sem foco na doença. Estudiosos identificaram, mediante consulta a revisões sistemáticas, uma quantidade expressiva de estudos empíricos em saúde e espiritualidade 
indicando que indivíduos com níveis mais elevados de R/E possuem menos problemas psiquiátricos ${ }^{24}$. Assim sendo, é mister que os trabalhadores tenham discernimento quanto a questões vinculadas R/E, uma vez que assim terão condições de identificar quando ela está funcionando como recurso terapêutico positivo de enfrentamento ${ }^{22}$.

A maior parte dos usuários afirma já ter compartilhado com trabalhadores o fato de fazer uso da religiosidade e que estes apoiam, acolhendo a sociedade com a sua cultura. Assim, acredita-se que as EqSF acolhem os aspectos religiosos ou espirituais presentes na vida dos usuários, respeitando todas as formas de crenças. Estudo indica que os pacientes julgam relevante sua dimensão espiritual no processo saúde-doença, reconhecem que a espiritualidade intervém na sua saúde, desejando que os trabalhadores os acolham nesse aspecto e discorram sobre esse tema ${ }^{25}$. Lembrando que o respeito aos valores dos usuários facilita o estabelecimento de vínculo entre eles e os trabalhadores da saúde ${ }^{25}$.

Existe a ideia de que toda religião estimula hábitos saudáveis. A mudança de hábitos pode dizer respeito à relação estabelecida com o uso de fármacos, onde a população tem o costume de tomar medicamentos sem necessidade, fortalecendo o processo de medicalização da vida. Recomenda-se o desmame de medicamentos e que se procurem soluções alternativas. Ou seja, assim como trabalhar a alimentação e a atividade física, trabalhar a R/E é enfatizar a saúde:

Mudar hábitos alimentares, praticar uma atividade física, um lazer, frequentar uma religião, tudo isso vai trazer um bem-estar para a pessoa e melhorar a qualidade de vida dela. (E5).

Acredita-se, nesse sentido, que pessoas ligadas a crenças religiosas fazem menos uso de medicamentos, sendo a $\mathrm{R} / \mathrm{E}$ uma aliada na redução do seu consumo. Impactante no autocuidado, a adoção de atitudes saudáveis por meio da religiosidade reforça o constatado em estudo 26 .
Existe uma eficácia simbólica por trás de rituais ligados a determinados tipos de religiosidade. Tal eficácia relaciona-se à crença ou fé no potencial de resolutividade que está contido em um objeto, santo, poção, erva etc. Considera-se, nessa direção, o impacto da fé. O conceito de eficácia simbólica ${ }^{3}$ tem sido utilizado para representar todo procedimento, particularmente os relacionados à cura, que fogem ao mecanicismo da perspectiva biomédica, a qual se pauta na relação causa e efeito para determinar a infalibilidade do tratamento. A eficácia simbólica indica outra dimensão, relacionada à ação e à experiência dos sujeitos, tomada na sua totalidade ${ }^{27}$.

\section{RELAC̣õES COM A BENZEDURA}

"Cada um no seu canto". (A6). "Cada um no seu canto tem o seu tanto". (B6).

Neste estudo, as perspectivas são distintas, oscilando entre diálogo e conflito. No que concerne ao 'conflito', este habitualmente se manifesta por parte do saber biomédico em relação ao que a benzedura recomenda para o tratamento das enfermidades, principalmente em relação ao tratamento de feridas com o uso de ervas. Além disso, há um limite imposto à benzedura, indicando que ela pode atuar, desde que não incentive o abandono do tratamento médico.

Quando a gente vê que tem muita coisa natural que realmente funciona e então o benzedor fala de uma planta medicinal, vamos supor: 'Eu vou benzer e ele vai usar essa planta', a gente embasa em estudos. Se aquilo realmente tem estudo que prova/comprova, porque a gente sabe que tem muito, não tem problema. (E2).

A benzedura, uma das representantes do saber popular, muitas vezes é depreciada pelo saber médico, que considera que aquela prática atrapalha na procura pelo tratamento ${ }^{\mathbf{1 2}}$. Quando as terapias populares tentam estabelecer relação com a medicina, lhes é exigida comprovação científica, e isso é muito comum 
em relação ao uso de plantas ${ }^{12}$. Segundo Bourdieu ${ }^{5}$, o mundo social é constituído por campos, cada qual com linguagem singular ${ }^{5}$.

É evidente a difícil e resistente comunicação, especialmente por parte dos médicos:

Nem todos acreditam. E principalmente os médicos. Porque os médicos acreditam piamente na medicina. Não são todos, mas $99 \%$ acredita na medicina. Cada um no seu canto. (A6).

Requer-se a submissão da benzedura à ciência médica e que aquela se embase no conhecimento científico. Percebe-se, assim, que os médicos defendem uma prática de saúde ainda pautada em um agir fragmentado, verticalizado e autoritário, que impõe o saber científico e desqualifica o saber popular, desprezando a participação da comunidade e desconsiderando seus conhecimentos ${ }^{20}$. A benzedura frequentemente contradiz a lógica da prática médica, tendo se desenvolvido frente a muitos embates e intolerâncias, visualizadas mediante preconceito e estigmatização ${ }^{9,13}$. Sabe-se que, na procura por autonomia e na disputa entre os campos, a tendência é se operar de forma que apenas seus porta-vozes e especialistas tenham o direito de dizer a verdade 5 .

Existem muitos tabus que fazem parte do imaginário dos trabalhadores da saúde em relação a práticas como a benzedura. Nesse sentido, não se percebe a possibilidade de concretização da parceria entre os diferentes saberes. Tal diálogo apenas se efetivaria por meio do profissional "sabido" (B2) ou dos médicos ditos 'espiritualistas': "Só os [médicos] que são espiritualistas. Porque a maioria são todos materialistas". (B7). O surgimento da homeopatia é tomado para exemplificar um momento de ruptura com a perspectiva biomédica tradicional, onde, a princípio, houve enfrentamento antes de ocorrer a acomodação:

Dentro da homeopatia houve um tempo inicial de enfrentamento, mesmo, dos médicos. Então uma ruptura ali de um padrão de medicina que não aceitava outro tipo de atividade que não fosse $a$ instituída, da medicina tradicional, que é a ocidental. Então, acho que a gente tem a fase de ruptura e isso talvez seja importante mesmo. (M3).

Movimentos inovadores no interior do campo, como o realizado por alguns médicos que propõem um novo modo de pensar a produção da saúde e do cuidado, podem ser uma forma de reação ao modelo preponderante de pensar a saúde ${ }^{28}$. Aqueles que monopolizam o saber convencional dentro do campo se colocam em oposição a novas propostas, numa reação automática ${ }^{28}$.

Relativamente ao 'diálogo', este se destaca em momentos em que benzedeiras ou benzedores e trabalhadores estabelecem uma boa parceria. Alguns médicos estão mais receptivos à R/E no tratamento do paciente, indicando, assim, que tem havido abertura, comunicação e caminhado para a convergência, ainda que seja um processo que ocorra em meio a barreiras. Ou seja, ainda que dificultosa, tem havido uma inflexão nessa relação. Tal fato pode ser verificado mediante a publicação intensa de artigos científicos sobre a relação entre religião e saúde, o que, por sua vez, tem resultado na introdução da temática da $\mathrm{R} / \mathrm{E}$ nas grades curriculares de diversas escolas de medicina ${ }^{22}$. Dessa maneira, percebe-se a habilidade do campo médico-científico em realizar o processo de retraduzir, ou seja, a sua capacidade em decompor os constrangimentos e exigências externas, ajustando-os à sua dinâmica própria ${ }^{29}$.

Trata-se de complementação, de ajuda adicional, vista como imprescindível. Cada um tem a sua função e pode contribuir a seu modo. É necessário abrir a mente para o fato de que uma prática não interfere na outra e que podem caminhar juntas. Há espaço na benzedura para se tratar de questões que não são possíveis junto à medicina, que não fornece respostas suficientes e não resolve tudo sozinha. Há uma especificidade de cada saber, onde um complementa o outro' . A terapêutica popular, por exemplo, possibilita aos sujeitos liberdade maior de expressão das suas demandas e até mesmo exteriorização 
dos seus sentimentos ${ }^{9}$, algo que não é visado pela medicina científica.

Quando o saber biomédico vem aliado à religiosidade e a práticas alternativas, pode proporcionar a maior parte das respostas, indicando que a medicina consegue trabalhar de forma integral quando é uma medicina espiritualizada e humanizada. Pode-se falar que, no interior do campo médico, tenha havido uma "redefinição das competências"30. Devido a uma nova composição no seu interior, além da medicina definida cientificamente, tem-se a medicina espiritualizada voltada para a integralidade dos sujeitos.

Os oficiantes dessa arte de curar enxergam a sua relação com os médicos no sentido de uma parceria positiva e uma comunicação viável. Do mesmo modo, os usuários entendem que haja associação entre saúde e benzedura. Estudo afirma que, em relação ao elenco de causas da enfermidade, os sujeitos não se restringem somente à apropriação da linguagem do discurso médico dominante. A este se agregam valores morais e explicações provenientes da religião, que refletem no modo como se simboliza o processo saúde-enfermidade ${ }^{31}$.

Tanto médicos quanto benzedeiras ou benzedores podem indicar entre si os usuários. Em algumas situações, os médicos encaminham para benzedeiras ou benzedores, que são eficazes para lidar com enfermidades mais simples: "Já teve caso do médico falar: 'Você sai daqui e procura uma pessoa que possa benzê-lo'. Cada um no seu canto tem o seu tanto" (B6). Por sua vez, há casos em que benzedeiras ou benzedores encaminham os usuários para os médicos, porque possuem habilidade para tratar de questões específicas:

Os guias ou mentores avisam. Se eles acharem que é deles, eles tiram. Agora, se eles acharem que não, eles mandam procurar o homem de branco, que são os médicos. (B2).

Em certas ocasiões, os trabalhadores da saúde sugerem que os usuários procurem por benzedeiras $\mathbf{1 2 , 1 3}^{\mathbf{1 3}}$. Por sua vez, as próprias benzedeiras, quando identificam que seu ritual e suas rezas não são satisfatórios, recomendam aos sujeitos que busquem o auxílio médico e a unidade de saúde ${ }^{9,10,12,13}$.

Se, conforme relatado pelos informantes, há momentos de diálogo e situações de conflito entre benzedeiras ou benzedores e trabalhadores, pode-se concluir que, na relação entre o campo da saúde e o campo religioso, o diálogo e o conflito podem tanto retroceder como progredir, dependendo da dinâmica de cada campo e em consequência do seu poder de retraduzir questões externas ${ }^{29}$.

\section{Conclusões}

A prática de benzedeiras ou benzedores é enxergada como parte da cultura brasileira. Porém, além de seu destaque como componente da cultura, a importância da benzedura tem relação com a defasagem do cuidado em saúde, que tem se distanciado de uma perspectiva holística do ser humano voltada para a escuta, o apoio e o fortalecimento dos sujeitos. A perspectiva biomédica tem operado mediante a medicalização da vida, destituindo os sujeitos do seu potencial cultural e de sua autonomia no enfrentamento de situações que envolvam sofrimento físico e psíquico. Percebeu-se que, consorciada à medicina, a benzedura é ajuda adicional que enseja trabalhar a totalidade do ser.

Este estudo, ao indicar o recurso a campos de saber distintos - a medicina e a benzedura - na explicação do processo saúde-doença-cuidado, trouxe à tona o antigo, porém atual, debate sobre a tensa relação entre ciência e religião. O diálogo entre os campos é possível graças ao incansável esforço dos usuários de colocá-los lado a lado e devido à espiritualização de alguns profissionais. A aproximação entre campo médico-científico e campo religioso é colocada em prática, diluindo o conflito e estabelecendo a comunicação.

Esta pesquisa poderá propulsionar outros estudos para a temática de terapias populares 
e sua relação com a produção de saúde e cuidado, bem como para a relação entre saúde e R/E, e, num âmbito mais amplo, entre ciência e religião.

\section{Colaboradores}

Assunção LM (0000-0001-6106-1200)* contribuiu para concepção e delineamento; análise e interpretação dos dados; redação do artigo; revisão crítica do artigo; aprovação da versão a ser publicada. Querino RA (00000002-7863-1211)* contribuiu para concepção e delineamento; análise e interpretação dos dados; revisão crítica do artigo; aprovação da versão a ser publicada. Rodrigues LR (00000002-1176-8643)* contribuiu para concepção e delineamento; análise e interpretação dos dados; aprovação da versão a ser publicada.

\section{Referências}

1. Ducati A, Dionísio B. Benzedeiras são consideradas profissionais da saúde no Paraná [internet]. Jornal Globo-G1. 2012 maio 11 [acesso em 2019 abr 21]. Disponível em: http://gl.globo.com/pr/parana/noticia/2012/05/benzedeiras-sao-consideradas-profissionais-da-saude-no-parana.html.

2. Costa EP. Benzedeiras no sistema oficial de saúde do Ceará: relações entre religiosidade e medicina popular [internet]. [dissertação]. São Paulo: Universidade Presbiteriana Mackenzie; 2009. 43 f. [acesso em 2019 abr 21]. Disponível em: http://tede.mackenzie. br/jspui/bitstream/tede/2534/1/Elizabeth\%20Parente\%20Costa.pdf

3. Lévi-Strauss C. A eficácia simbólica. In: Lévi-Strauss C. Antropologia estrutural. São Paulo: Cosac Naif; 2008. p. 201-20.

4. Silva ES, Lins GA, Castro EMNV. Historicidade e olhares sobre o processo saúde-doença: uma nova percepção. Revista Sustinere [internet]. 2016 [acesso em 2019 abr 21]; 4(2):171-86. Disponível em: https:// www.e-publicacoes.uerj.br/index.php/sustinere/article/view/25976/19514.

5. Bourdieu P. Razões práticas: sobre a teoria da ação. Campinas: Papirus; 1996.

6. Glaser BG, Strauss AL. The discovery of grounded theory: strategies for qualitative research. New York: Aldine de Gruyter; 1967.

7. Minayo MCS. O desafio do conhecimento: pesquisa qualitativa em saúde. 14. ed. São Paulo: Hucitec; 2017.

8. Conselho Nacional de Saúde. Resolução $n^{\circ} 466$, de 12 de dezembro de 2012. Aprova diretrizes e normas regulamentadoras de pesquisa envolvendo seres humanos [internet]. Brasília, DF: CNS; 2012 [acesso em 2019 abr 21]. Disponível em: http://bvsms.saude.gov.br/bvs/ saudelegis/cns/2013/res0466_12_12_2012.html.
*Orcid (Open Researcher and Contributor ID). 
9. Santos LG. A inserção das benzedeiras no meio popular (Pires do Rio e Palmelo) [internet]. [dissertação]. Goiânia: Pontifícia Universidade Católica de Goiás; 2016 [acesso em 2019 abr 21]. 98 f. Disponível em: http://tede2.pucgoias.edu.br:8080/bitstream/ tede/3363/1/LUENE\%20GONCALVES\%20DOS\%20 SANTOS.pdf.

10. Caldas MT, Alves MJS, Menezes AA. Benzeção e busca de sentido: uma reflexão a partir das práticas das benzedeiras. Rev Cult Teol. [internet]. 2016 [acesso em 2019 abr 21]; (87):161-77. Disponível em: http://revistas.pucsp.br/culturateo/article/view/rct. i87.28558/20045.

11. Azevedo GX. As benzedeiras na tecitura da cultura, religião e medicina populares [internet]. [tese]. Goiânia: Pontifícia Universidade Católica de Goiás; 2017. [acesso em 2019 abr 21]. 173 f. Disponível em: http:// tede2.pucgoias.edu.br:8080/bitstream/tede/3758/2/ GILSON\%20XAVIER\%20DE\%20AZEVEDO.pdf.

12. Hoffmann-Horochovski MT. Benzeduras, garrafadas e costuras: considerações sobre a prática da benzeção. Guaju [internet]. 2015 [acesso em 2019 abr 21]; 1(2):110-26. Disponível em: https://revistas.ufpr.br/ guaju/article/view/45038/27420.

13. Simões JP. Benzedeiras de Maruípe: uma prática de cuidado humano em extinção [internet]. [dissertação]. Vitória: Universidade Federal do Espírito Santo; 2014. 140 f. [acesso em 2019 abr 21]. Disponível em: http://repositorio.ufes.br/bitstream/10/1211/1/ Dissertacao.Juliana\%20Paereira\%20Simoes.pdf.

14. Marin RC, Comin FS. Desfazendo o "mau-olhado": magia, saúde e desenvolvimento no ofício das benzedeiras. Psicol Ciênc Prof. [internet]. 2017 [acesso em 2019 abr 21]; 37(2):446-60. Disponível em: http://www.scielo.br/pdf/pcp/v37n2/1982-3703pcp-37-2-0446.pdf.

15. Chalhoub S, Marques VRB, Sampaio CGR. Artes e ofícios de curar no Brasil: capítulos de história social. Campinas: Unicamp; 2003.
16. Archanjo LR, Leite DAT. A benzeção como prática terapêutica. In: Rasia JM, Lazzaretti CT. Saúde e Sistema Único de Saúde: estudos socioanalíticos. Curitiba: UFPR; 2014. p. 237-49.

17. Merhy EE. Em busca do tempo perdido: a micropolítica do trabalho vivo em saúde. In: Merhy EE, Onocko $\mathrm{R}$, organizadores. Práxis em saúde um desafio para o público. São Paulo: Hucitec; 1997. p. 71-112.

18. Rosário M, Sá LD, Klüppel BLP. Reza e tecnologia leve no diálogo entre os saberes científicos e populares. Ultimo Andar [internet]. 2014 [acesso em 2019 abr 21]; 23:93-112. Disponível em: https://revistas.pucsp. br/ultimoandar/article/view/19472/14430.

19. Hoffmann-Horochovski MT. Velhas benzedeiras. Mediações [internet]. 2012 [acesso em 2019 abr 21]; 17(2):126-40. Disponível em: http://www. uel.br/revistas/uel/index.php/mediacoes/article/ view/14025/11836.

20. Soares NA, Morgan BS, Santos FBO, et al. Crenças e práticas de saúde no cotidiano de usuários da rede básica de saúde. Rev Enferm UERJ [internet]. 2019 [acesso em 2019 abr 21]; 22(1):83-8. Disponível em: https://www.e-publicacoes.uerj.br/index.php/enfermagemuerj/article/view/11450/8988.

21. Marr L, Billings JA, Weissman DE. Spirituality training for palliative care fellows. J Palliat Med. [internet]. 2019 [acesso em 2019 abr 21]; 10(1):169-77. Disponível em: https://www.ncbi.nlm.nih.gov/pubmed/17298265.

22. Silva TD, Marques LF. Problematizações, desafios e possibilidades da inserção da religiosidade/espiritualidade $(\mathrm{R} / \mathrm{E})$ no contexto hospitalar brasileiro. Interações [internet]. 2016 [acesso em 2019 abr 21]; 11(20):98-114. Disponível em: http://periodicos. pucminas.br/index.php/interacoes/article/view/ P.19832478.2016v1ln20p98/10899.

23. Jönsson C, Lencastre L. Trauma e Religião: um modelo de adaptação psicológica baseado no coping religioso. Psicol. Saúde Doenças [internet]. 2016 [aces- 
so em 2019 abr 21]; 17(1):32-8. Disponível em: http:// www.scielo.mec.pt/pdf/psd/v17nl/v17nla05.pdf.

24. Bonelli RM, Koenig HG. Mental disorders, religion and spirituality 1990 to 2010: a systematic evidence-based review. J Relig Health. [internet]. 2013 [acesso em 2019 maio 6]; 52(2):657-73. Disponível em: https://doi.org/10.1007/s10943-013-9691-4.

25. Oliveira GR, Neto JF, Salvi MC, et al. Saúde, espiritualidade e ética: a percepção dos pacientes e a integralidade do cuidado. Rev Soc Bras Clín Méd. [internet]. 2013 [acesso em 2019 abr 26]; 11(2):140-4. Disponível em: http://files.bvs.br/upload/S/1679-1010/2013/ v1ln2/a3566.pdf.

26. Zerbetto SR, Gonçalves AMS, Santile N, et al. Religiosidade e espiritualidade: mecanismos de influência positiva sobre a vida e tratamento alcoolista. Esc Anna Nery Rev Enferm. [internet]. 2017 [acesso em 2019 abr 26]; 21(1):e20170005. Disponível em: http://www.scielo.br/pdf/ean/v21n1/1414-8145-ean21-01-e20170005.pdf.

27. Tavares F, Bassi F, organizadoras. Para além da eficácia simbólica: estudos em ritual, religião e saúde. Salvador: EDUFBA; 2012.
28. Bourdieu P. Questões de sociologia. Rio de Janeiro: Marco Zero; 1983.

29. Bourdieu P. Os usos sociais da ciência: por uma sociologia clínica do campo científico. São Paulo: UNESP; 2004.

30. Bourdieu P. Coisas ditas. São Paulo: Brasiliense; 2004. [acesso em 2020 set 1]. Disponível em: https://nepegeo.paginas.ufsc.br/files/2018/06/BOURDIEU-Pierre.-Coisas-ditas.pdf.

31. Separavich MAA, Canesqui AM. Representações religiosas na experiência com a enfermidade: um estudo de caso. Cad. Saúde Pública [internet]. 2016 [acesso em 2019 abr 2]; 32(3):e00024915. Disponível em: https://www.scielosp.org/pdf/csp/2016.v32n3/ e00024915/pt.

Recebido em 06/09/2019

Aprovado em 23/05/2020

Conflito de interesses: inexistente

Suporte financeiro: não houve 